From the Editor

\title{
Deepal S. Weerasekera introduces the final issue of 2011
}

Sri Lanka Journal of Obstetrics and Gynaecology 2011; 33: 141

Welcome to the final edition of "The Sri Lanka Journal of Obstetrics and Gynaecology" for 2011. This will also be the final edition of which I will be the editor. From year 2012 there will be a new editor to the Journal.

In this edition we have the commentary on domestic violence which is an emerging concern in maternity care. This is an unrecognized problem of immense magnitude which really needs more attention by our members. Written by Dr Lakshmen Senanayake, who has a vast experience in this subject, our Sri Lankan situation is well depicted in relation to the global perspective. Dr Lakshmen Senanayake has been involved in many research projects and activities on domestic violence throughout Sri Lanka. He has critically analyzed and assessed the impact of domestic violence in pregnancy in this commentary.

In the first of our research papers we publish a very interesting study from India analyzing the outcome of premature rupture of membranes in HIV infected women. This is a study spanning over 8 years screening 17040 pregnancies. The extent of the HIV in India is reflected by the prevalence rate of almost $0.4 \%$. Effect of anti-retroviral prophylaxis in preventing vertical transmission of the disease is well analyzed in this study. In the second paper the importance of systematic obstetric ultrasound training is well highlighted. Dr Tiran Dias has been involved in conducting many training workshops in obstetric ultrasound scanning in various parts of Sri Lanka over the past few years. This study shows that obstetric ultrasound skills among those who perform ultrasound scanning in Sri Lanka needs to be improved. We all are well aware that substandard scanning do more harm than any good. The value of a properly organized training programme to meet this requirement is emphasized in this paper.
Asymptomatic bacteruria is a common problem which all of us encounter as practicing obstetricians. In our third research paper which is a community based study, the importance of screening and the causative organisms and their antimicrobial susceptibility patterns are well analysed.

Featured prominently are four rare case reports which are conditions important to be aware by all practicing obstetricians and gynaecologists. These case reports are extremely interesting reading matter.

We as practicing obstetricians encounter more and more women pregnant with cardiac disease. Although the incidence of rheumatic heart disease has drastically decreased more and more women with congenital heart disease now survive to adulthood and become pregnant. This review article is timely and is a comprehensive review of the present day management of various cardiac problems encountered in pregnancy.

In the continuous professional development section the series continues on importance of ultrasound scanning and management of female urinary incontinence. Dr Tiran Dias elaborates very clearly the significance of structural anomalies that can be diagnosed by scanning in the first trimester. In the second article Dr Ruwan Fernando continues very simply and clearly the importance of basic investigations in urinary incontinence. Dr Asoka Weerakkody continues with his approach of making statistics simple which I am sure that all our post graduates will find it really useful. Also answers for questions asked in the revision exercise in the previous issue is given so that you can make a self assessment as to where you stand. I hope you will find the journal providing good reading material and finally all that remains is for me to send you my best wishes for 2012. 